Revista Iberoamericana, Vol. LXXX, Núm. 246, Enero-Marzo 2014, 147-159

\title{
JOSÉ DONOSO EN EL EJERCICIO DE COMPOSICIÓN DE LA CASA DE EJERCICIOS ESPIRITUALES DE LA ENCARNACIÓN DE LA CHIMBA: UNA INTERPRETACIÓN A PARTIR DE LOS JOSÉ DONOSO PAPERS ${ }^{1}$
}

\author{
POR \\ María Laura Bocaz Leiva \\ University of Mary Washington
}

\begin{abstract}
Anovel is, besides many other things, a story. What could conceivably be useful, or at least amusing, would be to append to that story a kind of biography of it: not what it is or what it is meant to be but how it all happened. Thus, a clutter of rattling trailers could become attached to the rear end of the sleek racing car that is a good novel and make it, perhaps, less forbidding.

José Donoso, “A Small Biography of The Obscene Bird of Night”
\end{abstract}

José DONOSO PAPERS: DOS ARCHIVOS, Un ESCRITOR

La colección José Donoso Papers se encuentra distribuida en dos archivos. Al igual que tantos otros aspectos relacionados con la figura de Donoso, los motivos y circunstancias en las que sus materiales de trabajo y algunos de carácter más personal pasaron a formar parte de dos colecciones diferentes constituyen en el presente casi una leyenda cuya cantera son precisamente los viscerales testimonios del autor. Donado o vendido sólo por necesidad, el hecho es que actualmente el investigador cuenta con un corpus reunido, organizado y entregado voluntariamente por el escritor, compuesto por múltiples cuadernos de escritura, versiones mecanografiadas pertenecientes a diferentes proyectos publicados e inéditos, correspondencia, fotografías y recortes de prensa, que data desde $1950 .^{2}$

1 Quiero agradecer especialmente a Daniel Balderston por su generosidad y por organizar e invitarnos a participar en el simposio "Genetic Criticism and Latin American Texts" en abril de 2011. A Kathryn Hodson y Sidney Huttner, de la sección de Colecciones especiales de la Universidad de Iowa, por su ayuda con las imágenes incluidas en este trabajo.

2 Para un testimonio del origen de la colección en la Universidad de Princeton ver "Corresponding Archives: Letters from the Latin American Literary Front”, de Lucille Kerr (77). 
El material que cubre desde la década del 50 hasta 1966 se encuentra en la sección de Colecciones Especiales de la Universidad de Iowa. Incluye principalmente cuarenta y siete cuadernos de trabajo y versiones mecanografiadas de diferentes obras, correspondencia personal, así como material escritural y cartas recibidas por su esposa María Pilar Serrano. El material relacionado con la escritura de El obsceno pájaro de la noche comprende diecinueve cuadernos, los que abarcan principalmente desde el 14 de marzo de 1959 hasta el 5 de diciembre de 1965.

El archivo de la Universidad de Princeton, por su parte, contiene los cuadernos de trabajo a partir de enero de 1966, nueve de los cuales corresponden al proyecto de escritura del Obsceno pájaro. También incluye correspondencia, versiones mecanografiadas y dos carpetas de fotografías. La colección ha sido abierta para consulta del público general a partir de mayo de 2009; no obstante, la duplicación de material está restringida.

En el presente artículo me propongo interpretar el proceso de composición de lo que en el estado édito de la novela corresponde a los fragmentos relacionados con la Casa de Ejercicios Espirituales de la Encarnación de la Chimba. Específicamente, discuto el ejercicio de desdibujar la ubicación exacta de esta casa en la urbe, dinámica que opera básicamente en dos etapas, una primera donde el escritor define claramente el emplazamiento de la casa en la ciudad y una segunda en la que borra algunos de los elementos que permitían determinar en diversos estados textuales su localización en Santiago. Para ello voy a focalizarme en la interpretación de anotaciones metaescritutarias, pretextos preparatorios y material redaccional, presentes en los cuadernos de trabajo, así como en el cotejo de la versión édita con estados textuales anteriores.

La CASA de Ejercicios Espirituales de la EnCARNACión dE LA CHIMBA EN LOS MATERIALES DE TRABAJO DE JosÉ DONOSO

En el estado textual édito de la novela, la Casa de Ejercicios Espirituales constituye un edificio en ruinas, "un laberinto de murallones carcomidos y solitarios" (108), donde moran un grupo de ex sirvientas, huérfanas, tres monjas y el personaje Mudito. Además de habitación, la casa sirve de depósito para los muebles que ya no caben en las residencias, de los zapallos que estorban por su abundancia y de aquellos restos de adoración religiosa a los que los creyentes temen tratar como escombros: "sí, claro, no se puede tirar a la basura los fragmentos de objetos que han sido de culto, hay que respetarlos, no se les puede confundir en el basurero con los desperdicios de la comida y el aseo, no, hay que traerlos a la Casa de Ejercicios Espirituales de la Encarnación de la Chimba, donde todo cabe" (79).

Las anotaciones autógrafas del escritor en el cuaderno 28 sugieren que el núcleo de la Casa de Ejercicios se incorpora en forma definitiva a la novela Obsceno pájaro a partir de 1964, mediante la adición del personaje Humberto Peñaloza como uno

Revista Iberoamericana, Vol. LXXX, Núm. 246, Enero-Marzo 2014, $147-159$
ISSN 0034-9631 (Impreso) 
de sus habitantes. Solo dos anotaciones previas en los cuadernos 21C y 22 de 1962 constituyen antecedentes del edificio y de una de las escenas que ocupa un lugar central en este núcleo, a saber, el funeral de Brígida. En el cuaderno 21C, se accede al escritor interesado en incorporar al personaje Peta Ponce del Obsceno pájaro a una casa de la que solo tiene referencias: “¿Cómo incorporar a la Peta a la casa de que habla la Poli del Río, donde su madre tiene un guardadero, ex convento, lleno de harapos humanos, semi-monjas, semi-beatas? . . p poder incorporar, tal vez, el guardadero como puesto lateral, como un side-story" (24-26).

En el cuaderno 22, por su parte, se observa que el escritor en medio de la desesperación porque no logra avanzar con "El Último Azcoitía”, piensa en la posibilidad de escribir otra novela a la que titularía "Funeral para un ángel”:

\section{FUNERAL PARA UN ANGEL}

31 julio

De pronto, una novela completamente distinta a la novela Santiaguina y al Azcoitía . . . . La novela podría llamarse "Funeral de un ángel” y es, simplemente, la narración de un funeral y las visiones de los distintos asistentes y deudos de el/la muerta. Comienza en la casa del muerto, en el velorio mientras se juntan los autos para ir al cementerio ... la misa en la capilla del cementerio y por último la sepultación de los restos en un nicho cualquiera. (NB22: 125-26)

Las anotaciones que materializan el momento en que la casa pasa a formar parte de la novela Obsceno pájaro, se encuentran en el esquema prerredaccional que inaugura el cuaderno 28, a partir del cual se infiere que Donoso ha decidido dividir su novela en cinco partes y dedicar la segunda a la Casa. Como se puede ver en el fragmento que cito a continuación, el escritor quiere utilizar un estilo clásico, lineal para narrar esta segunda parte de su novela:

\section{$2^{\mathrm{a}}$ parte - Casa de Ejercicios}

Esta parte tiene que estar escrita à la Dickens, argumento, tranquila, al paso del tiempo en la casa de ejercicios, las intrigas y los dolores. Anciano solo, sacerdote agoniza en una pieza. Monjas aristocráticas, idiotas ... señoras que van a ver los muebles guardados. Muchachos que pasan una semana en ejercicios. Ancianas decrépitas en los patios y cocinan y se pelean. El mundo de afuera, los niños que juegan al fútbol. ... La niña que vió a su padre matar a su madre de un hachazo pololea con el de afuera que juega fútbol. (NB28: 1-2)

Uno de los aspectos que resulta importante subrayar es que Donoso piensa esta segunda parte de la ficción total como una novela en sí misma, tanto en términos argumentales como en lo que respecta a la disposición de los acontecimientos narrados: "Desarrollo de la segunda parte ‘Ejercicios Espirituales'. ... Desde luego concebir esta parte como una novela aparte, dentro de la cual, Humberto es uno de los personajes” (NB28:51).

\footnotetext{
Revista Iberoamericana, Vol. LXXX, Núm. 246, Enero-Marzo 2014, 147-159 
La primera opción de textualización que el escritor considera consiste en hacer una presentación de la casa donde se especifiquen sus características y ubicación en la ciudad: “¿Por qué no comenzar en la forma clásica y tranquilamente pasada de moda -con una descripción de la casa de ejercicios espirituales, su emplazamiento en la ciudad, y el barrio que la rodea, etc. Y de allí sacar el hilo narrativo?” (NB28:52).

Después de sucesivas páginas en las que se observan anotaciones que retratan al escritor debatiéndose entre diferentes posibilidades para inaugurar esta segunda parte del Obsceno pájaro, se encuentra un comentario que a mi parecer resume cabalmente el conflicto de textualización que este nuevo núcleo genera en el escritor:

Hay cosas que no entiendo: dos modos me seducen -el clásico, lineal, argumental (*) de "Coronación”, y el romántico, sinfónico, compuesto de muchas partes distintas ("Sobre héroes y tumbas") que pueden parecer desconectadas. Ahora a mi [sic] me parece que SIENTO mas [sic] la primera forma -pero me gustaría intentar la segunda. ... Voy a releer esta noche "Sobre héroes y tumbas". (NB28: 65) ${ }^{3}$

A partir de las características que definen la obra de Donoso en mayo de 1964 -un conjunto de cuentos y su novela Coronación, de 1957-donde sólo pueden identificarse atisbos de una experimentación con la forma, se puede deducir que, de esos "dos modos que seducen", es el "sinfónico" el que en este punto de su carrera lo abruma. Como se verá más adelante, el estilo que predomina en la novela de la Casa es el tradicional. No obstante lo anterior, si se atiende a diversos estados textuales, es posible identificar adelantos de la incorporación de ese segundo estilo que, a juzgar por la versión édita de la novela, consiste en la yuxtaposición de diversas voces narrativas, en la introducción de cambios abruptos en el punto de vista, lo que da como resultado la ambigüedad e indeterminación.

A ese anhelado cambio que dificulta y moldea el proceso de composición del Obsceno pájaro, se suma la intención creativa de incorporar la ciudad a su ficción. Específicamente, se trata de un Santiago que ha cambiado dramáticamente como consecuencia de la modernización y la dinámica entre sus clases sociales:

Quiero hacer de esta novela algo muy importante- la novela del Barrio Bajo: la ciudad se ha movido hacia el Barrio Alto, dejando allá otra vida. ... ¿Cómo incorporar esta ciudad abandonada al fluir de la novela? Probablemente a través de Iris-sus relaciones en los dancings, por ejemplo. En las fuentes de Soda de San Pablo esquina de Matucana (el paso del tren todavía funcionaba), los negocios de fierro viejo. (NB29: 26-27)

3 Utilizo el signo (*) para señalar que no estoy segura de la interpretación de la caligrafía.

ISSN 0034-9631 (Impreso)


A partir de la anotación que sucede a esta declaración (Figura 1), propongo que para responder a esta intención creativa Donoso decide ir a recorrer la ciudad: "Estoy entusiasmado con la idea del Barrio Bajo, la primera parte de la novela del Barrio bajo. Voy ya con M. Pilar a verlo” (NB29: 28). La caligrafía de trazo apurado y difícil

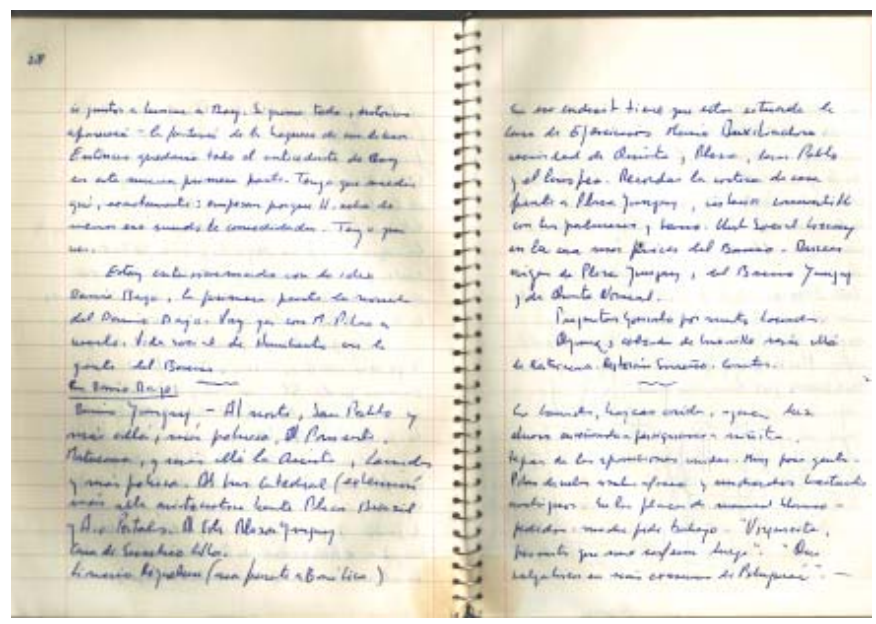

Figura 1

de descifrar con la que se inscribe el párrafo que sigue a esta declaración (Figura 1), sugiere que el escritor ya no escribe en la comodidad de su escritorio, sino que toma notas mientras desarrolla la añorada visita:

En Barrio Bajo:

Barrio Yungay, -Al norte, San Pablo y más allá, más pobreza. Poniente, Matucana, y más allá la Quinta, Lourdes $\left({ }^{*}\right)$ y más pobreza. Al Sur Catedral (extensión más allá aristocratica [sic] hasta la Plaza Brazil [sic] y Av. Portales. Al Este Plaza Yungay. Casa de Eusebio Lillo.

Sinesio Riquelme (Casa frente a Basílica) En ese endroit tiene que estar situada la Casa de Ejercicios María Auxiliadora: necesidad de Quinta, Plaza, san Pablo y el lumpen (*). Recordar la corteza de casa frente a la Plaza Yungay, interior convertible (*) con tres palmeras y barro (*) Club Social (?) En la cada más pobre (*) del Barrio Yungay y de Quinta Normal. (NB29: 28-29)

Propongo interpretar estas anotaciones como un plano mental que tiene por punto de partida al Barrio Yungay, como un ejercicio que responde al anhelo de Donoso de tomar control del sector. El mapa cubre cuatro direcciones: al norte, San Pablo; al poniente, Matucana; al norponiente, la Quinta Normal; al sur, catedral. Ahora bien, las anotaciones no sólo proveen información geográfica; el escritor también registra observaciones que

Revista Iberoamericana, Vol. LXXX, Núm. 246,
ISSN 0034-9631 (Impreso) 
hablan de la distribución de clases sociales dentro de la urbe: "Al norte, San Pablo y más allá, más pobreza”; “Al Sur Catedral (extensión más allá aristocratica [sic] hasta la Plaza Brazil [sic]”.

A continuación de estas notas se encuentra un párrafo que presenta una caligrafía de trazo aún más apurado, dificultando su decodificación (Figura 1):

En Lourdes hojas caídas(*), agua luz abuelo(*) enseñando a persignarse a niñita, tapas de las apariciones $\left(^{*}\right)$ corridas. Muy poca gente. ... En la placa de Manuel Blanco (*)- pedidos: madre pide trabajo. "Virgencita, permite que me enferme luego". "Que salga bien en mis examenes [sic] de Peluquería”. - San Gumercindo, calle (?) Que se mete en una manzana, dobla, cabbled. Mucho barro, mucho adobe. Limpieza de día después de la lluvia. TROM-PEZÓN. Iris quisiera estudiar peluquería-peinados moda de liceanas esperando micro. (NB29: 29-30)

La forma como se inaugura la anotación me invita a proponer que Donoso se ha trasladado a la gruta dedicada al culto de la Virgen de Lourdes, ubicada en el sector de la Quinta Normal. En esta oportunidad el escritor se centra en tomar notas de lo que observa. Igualmente, toma notas de las placas que sintetizan o registran las peticiones de los fieles.

La referencia a la calle San Gumercindo (Figura 2) que aparece a continuación del registro de las peticiones, sugiere que Donoso no se ha contentado con permanecer en la gruta, sino que ha decidido salir a caminar por los alrededores. Esta vez centra su atención en las características del sector "Mucho barro, mucho adobe"; en el hecho de que algún vecino esté haciendo una limpieza "después de la lluvia”. La anotación se cierra con lo que interpreto como una idea a trabajar en la novela de la casa, ya que Iris es el nombre de una de las huérfanas asiladas y, como se verá más adelante, uno de los personajes que adquiere un lugar protagónico en este núcleo: "Iris quisiera estudiar peluquería- peinados moda de liceanas esperando micro” (NB29: 29-30).

A continuación se observa una separación en el espacio de la página, materializada mediante el trazado de una línea irregular(Figura 2) al que sigue otro párrafo de anotaciones de caligrafía aún más atropellada, dificultando enormemente su decodificación: “Calle Herrera Clinica [sic] Dental. Esperanza Calle-Libertad-Sotomayor . . . compraventa y cambio de libros y revistas. Progreso calle corta. Muñecón gigante de propaganda: Iris puede pololear con eso (*)" (NB 29: 30). Propongo que en esta oportunidad, el escritor se ha desplazado hacia el este de la ciudad, probablemente a través de la calle San Pablo, pasando por las calles perpendiculares Herrera, Esperanza, Libertad y Sotomayor. Esta

\footnotetext{
4 Para comprender la petición "Virgencita permite que me enferme luego" es necesario considerar el significado que el verbo "enfermarse" tiene en el español chileno, donde corresponde al vocablo que en un registro coloquial se utiliza para referirse al ciclo menstrual. De este modo, interpreto esta petición como un ruego dirigido a la Virgen, por parte de una mujer angustiada por un embarazo no planificado.
}

Revista Iberoamericana, Vol. LXXX, Núm. 246,
ISSN 0034-9631 (Impreso) 
vez las anotaciones no se centran en las características del barrio, sino en el comercio: “Clinica Dental”, “compraventa y cambio de libros y revistas” (Figura 2).

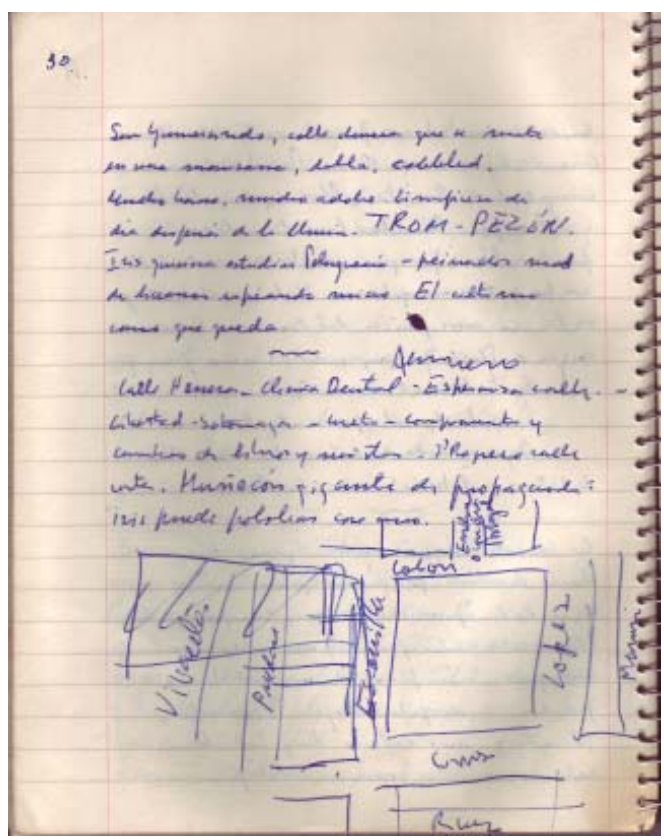

La siguiente anotación corresponde a un dibujo de trazo también apurado en el que se observan diversos cuadrantes y nombres de calles registradas con una caligrafía ocasionalmente ilegible, entre las que decodifico Vivaceta, Escanilla, Colón, López, Cruz, Rivera y Maruri (Figura 2). Los cuatro cuadrantes que ocupan el lado izquierdo del plano presentan una línea irregular sobrepuesta que propongo interpretar como una anulación de la representación hecha previamente (NB29:30). A continuación del plano se observa un listado de calles entre las cuales aparecen varias de las avenidas especificadas en el plano que la precede (Figura 2).

Una breve línea de trazado irregular nuevamente separa la siguiente anotación. En esta se observa un cambio radical en la caligrafía al presentar un trazado más reposado (Figura 3). Este hecho en conjunción con el registro de una fecha -4 de junio de 1964- y la afirmación entusiasta "Buena excursión ayer” permiten inferir que las anotaciones que siguen corresponden al escritor trabajando nuevamente en el espacio de su escritorio (NB29: 31).

Siete páginas más adelante en el mismo cuaderno, se encuentra el dibujo de un plano trazado cuidadosamente con bolígrafo de color azul, que ocupa todo el espacio de la

Revista Iberoamericana, Vol. LXXX, Núm. 246,
ISnero-Marzo 2014, 


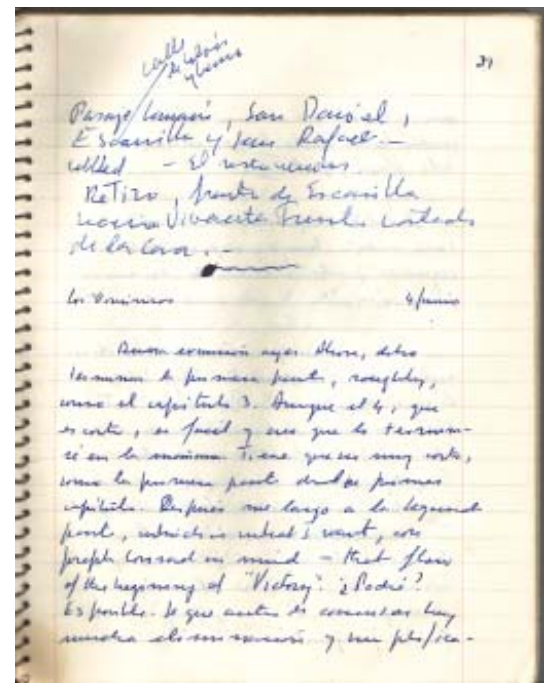

Figura 3

página (Figura 4). La coincidencia en el nombre y ubicación de las calles, así como las diferencias que presentan los cuadrantes del lado izquierdo con el fragmento anulado en el plano anterior, me invitan a proponer que constituye una segunda versión construida a partir del plano esbozado con rapidez durante la excursión desarrollada previamente. En esta segunda versión destaca inmediatamente a la vista el cuadrante ubicado entre las calles Cruz, Escanilla, Colón y López debido a que es el único que ha sido coloreado con un lápiz de color e identificado como “Casa de Ejercicios” (NB29:38).

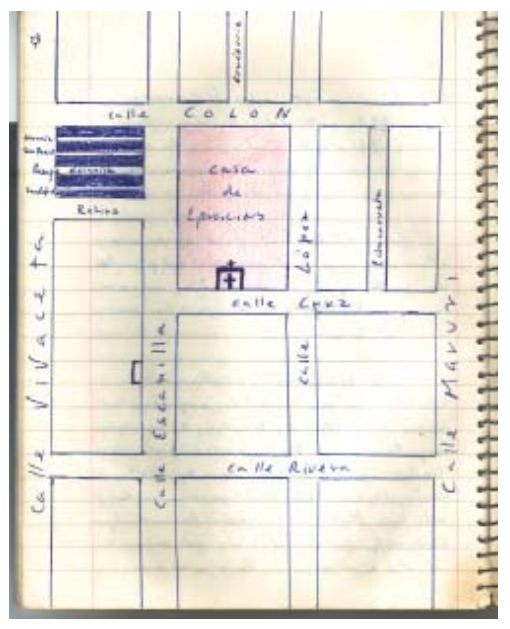

Figura 4

Revista Iberoamericana, Vol. LXXX, Núm. 246, Enero-Marzo 2014, $147-159$
ISSN 0034-9631 (Impreso) 
Uno de los rasgos que llama la atención en los borradores autógrafos y anotaciones prerredaccionales que siguen a las notas tomadas durante el recorrido por la ciudad, es el protagonismo que adquieren las calles. Por ejemplo, se puede ver que el escritor no sólo quiere describir la llegada de un camión a la Casa de Ejercicios, sino su recorrido: "El camión en el atardecer de invierno, avanzando por las calles, la calle Escanilla, calles embarradas, calle Cruz” (NB29: 34). De igual modo, en el breve pasaje que cito a continuación se aprecia que el escritor se esfuerza por especificar por medio de las calles, el sector de la ciudad en donde ha decidido ubicar la Casa: “Al otro lado del río, entre Independencia y Vivaceta, hay un barrio viejo y tranquilo, que a pesar de no estar tan retirado del centro [sic]. Por encima de sus techos, diez cuadras más al sur, y por una bocacalle, se alcanza a divisar algún rascacielo del centro” (NB29: 36).

En los estados textuales que cito a continuación, se puede ver que el escritor decide aprovechar las escenas protagonizadas por Iris y el Gigante repartiendo volantes de los almacenes Martín Pescador, para especificar la ubicación del inmueble:

Iris y el mono [el Gigante] vienen por la calle Retiro. Descripción, y entran por la calle Escanilla. Ahí el mono se sienta un rato en un banco y a oír radio. La señora le dice que se vaya, que lo van a echar, que todas las tardes se lo pasa tonteando con la Iris y no camina nada. Toman por la Calle Cruz hacia Independencia. ... Los muchachos jugando fútbol, chiflan, entre Mauri y López, ella corre porque ve al camión en la puerta de la casa [el que viene a dejar el cargamento de zapallos]. (NB29: 39)

"El mono la lleva de la mano, van conversando. Doblan al Sur por Escanilla. ... Pasan de largo por la calle Cruz. ... Salen, van por Cruz hasta López”. (NB29: 41-42)

El lugar central que Donoso otorga a las calles en los borradores y anotaciones autógrafos coincide con las primeras versiones mecanografiadas relacionadas con este núcleo. El borrador titulado inicialmente "capítulo 5" y que en una relectura el escritor titula “Segunda parte, capítulo 9”, se abre con una escena que describe el recorrido de Iris con el Gigante, en este estado textual "Martín Pescador”: "Por la calle Vivaceta, los chiquillos los persiguieron un rato, pero Martin [sic] les lanzó los últimos volantes que le quedaban, lo que los detuvo, no sin que uno antes lanzara una piedrecita que rebotó en la enorme cabeza hueca de Martin [sic]. Pero aprovechó para apurar el paso, seguido de Iris, hasta llegar a la esquina de la calle Retiro y doblar por allí” (37).

El recorrido de ambos personajes continúa por la calle Escanilla. Como se podrá ver a continuación, el fragmento incluye algunas de las observaciones sobre el comercio del barrio, registradas en el cuaderno 29 durante la excursión:

Siguieron hacia escanilla [sic]. En ese costado de la casa de María Auxiliadora, en sus paredones acogedores como piel gruesa y vieja, se habían ido organizando pequeñas vidas privadas que nada tenían que ver con la Casa- un taller de bicicletas en torno al cual circulaban los muchachos ... una pieza que vendía e intercambiaba libros y

Revista Iberoamericana, Vol. LXXX, Núm. 246, Enero-Marzo 2014,
ISSN 0034-9631 (Impreso) 
revistas viejas-incrustadas todas como garrapatas bajo la piel acogedora de la casa de Ejercicios Espirituales, viejas de adobón, de dos pisos, que ocupaba la manzana entera. Doblaron por la calle escanilla [sic]. (39)

Por su parte, el borrador titulado “Capítulo Seis” se abre con la ubicación de la casa. Esta vez, sin embargo, el narrador hace referencia al barrio:

La Casa de Ejercicios Espirituales de María Auxiliadora ocupa una manzana entera en el barrio Viavaceta. ... Esta [sic] emplazada allí desde antes que se poblara ese sector poniente de la Chimba, cuando no era otra cosa que una serie de quintas de hortaliceros que llevaban en carreta su producto a la capital, atravesando el río por el puente de Cal y canto, antes de que ese barrio se llamara Vivaceta, antes de que don Fermín echara sus discursos en los sindicatos, antes de que Pablo Neruda de capa y plastrón y flaco como una ganzúa cantara a los crespúsculos morados de la calla Maruri. (44)

Al contrastar estos estados textuales con la versión édita, resalta en la segunda la ausencia de los nombres de las calles y por tanto un desdibujamiento de las coordenadas que determinan la ubicación exacta de la habitación en la ciudad. Así, mientras en los borradores autógrafos y en un conjunto de versiones mecanografiadas el lector tiene acceso al barrio y las calles que la rodean, en la versión publicada sólo puede inferirse su ubicación. De este modo, propongo que en la incorporación de ese complemento al nombre de la Casa, que a primera vista puede resultar accidental -de la Chimba-, el escritor permite reducir su ubicación a un sector dentro de la ciudad. Como resultado, el lector de la novela publicada sólo puede inferir en el presente narrativo que la Casa se encuentra relativamente cerca del centro cívico de la ciudad: "el Gigante me va a llevar a uno de esos edificios altos que se ven allá en el centro" (30); que se trata de un "barrio bullanguero", de "casas modestas" con techos tejados (63), donde priman peluquerías, panaderías, cantinas, talleres de reparaciones, "negocio de compra-venta de novelas y revistas usadas" (63). Asimismo, que se trata de un sector antiguo donde prima el adobe: "no va a costar nada demolerlo [el edificio de la Casa], es puro adobe o tabique de barro" (547). Por último, que corresponde a un sector intrínsecamente relacionado con los orígenes de la capital:

Abandonado a las necesidades sin concierto de distintos tiempos, este edificio creció tanto y tan anárquicamente. . . . La ciudad cruzó el río hacia el norte y se pobló esa orilla. Se organizaron callejuelas miserables que fueron desplazando más y más lejos las chacras cuyos tomates y melones nutrían a la ciudad, hasta que las callejuelas de la Chimba, al avanzar, se transformaron en avenidas con nombres de reivindicadores de derechos obreros, y al rodear y dejar a tras la Casa de Ejercicios Espirituales de la Encarnación de la Chimba, la enquistaron, muda y ciega, en un barrio bastante central.(60)

Revista Iberoamericana, Vol. LXXX, Núm. 246,
ISSNero-Marzo 2014, 
Cabe señalar, sin embargo, que este anexo del complemento "de la Chimba" al nombre de la Casa se realizó tardíamente. No fue hasta 1969 que esa Casa denominada en diferentes estados textuales como "Casa de María Auxiliadora”, "Casa de Ejercicios de la Preciosa Sangre”, pasa a llamarse "Casa de Ejercicios Espirituales de la Encarnación de la Chimba”. En el estado textual que cito a continuación se puede observar que en sus inicios, la referencia a la Chimba es utilizada únicamente para referirse a las características de la zona donde se construye la casa:

Allado afuera de la capital, atravesando el puente de Cal y canto, en la región denominada como la Chimba, él [don Jerónimo] poseía una riquísima chacra, con buena agua y fértiles tierras como todas las de la región. Grandes carretas abandonaban la Chimba en la mañana . . . cargadas de zapallos y de tomates y de acelgas y de melones, y en lenta caravana atravesaban las vegas de la Chimba, y cruzando el puente llegaban al mercado a vender sus productos. Esa chacra, en buena tierra, don Jerónimo la colocó en capellanía: construyó una casa con patios y huertos para alojar a su hija y a las monjitas y dispuso que fuera una casa para que la gente principal de la capital hicieran sus Retiros Espirituales. (B10, F14: 6 José Donoso Papers, PU)

\section{CONCLUSIONES}

La interpretación de los materiales de trabajo que dan cuenta del proceso de composición del núcleo relacionado con la Casa de Ejercicios permite incorporar a nuestra lectura del Obsceno pájaro la perspectiva del escritor José Donoso en pleno ejercicio de composición de su novela más ambiciosa en términos de experimentación formal. Dentro de este marco resalta el conflicto que a partir de 1964 genera en el escritor el anhelo de incorporar un nuevo estilo de escritura radicalmente opuesto al que caracterizaba a su ficción de la década del cincuenta. Ala luz de los cuadernos de trabajo esta tensión que determina y dificulta el proceso de composición del Obsceno pájaro se revela como uno de los productos de la lectura crítica de las novelas de Julio Cortázar, Ernesto Sábato, Carlos Fuentes y Mario Vargas Llosa, durante la década del sesenta.

En el caso específico del núcleo aquí estudiado, esa tensión se observa entre la especificación y posterior desdibujamiento de la ubicación de la Casa en la ciudad. El ejercicio de desdibujar la localización del inmueble -dando como resultado uno de los primeros elementos que permitieron al escritor dar cabida a la ambigüedad en su ficción- radicó básicamente en dos movimientos. Por una parte borrar paulatinamente el nombre de las calles que rodeaban a la Casa y por otra incorporar a su denominación el complemento "de la Chimba".

El estudio e interpretación de los materiales de trabajo relacionados con la Casa también permite entablar un diálogo con las lecturas que la crítica textual ha ofrecido a partir de la novela en su estado édito. Richard Browning en "La arquitectura de la

\footnotetext{
Revista Iberoamericana, Vol. LXXX, Núm. 246, Enero-Marzo 2014, 147-159 ISSN 0034-9631 (Impreso) ISSN 2154-4794 (Electrónico)
} 
memoria: los edificios y sus significados en 'El obsceno pájaro de la noche' de José Donoso", discute la posibilidad de que el autor se hubiera inspirado en el convento de El Carmen de San Rafael o del “Carmen Bajo” para la creación de la Casa de Ejercicios. Basa su hipótesis en la ubicación y numerosas coincidencias que se aprecian entre ambos inmuebles desde el punto de vista de su arquitectura, origen y características:

\begin{abstract}
Puede que Donoso haya pensado en una como el convento de "El Carmen de San Rafael”, también llamado "Carmen Bajo”, del barrio de la Chimba, construido a fines del siglo dieciocho por el Corregidor Zañartu con el propósito de dedicar a sus dos hijas a la vida religiosa. [...] Para 1770 estuvo terminado el convento y se mudaron allí cuatro monjas del Convento Carmen de San José. [...] Se ha difundido también una leyenda (no recontada en detalle por Echaíz) acerca de cómo sobrevivieron las monjas una inundación en 1783 (Echaíz 1: 121), un desastre que se parece mucho al terremoto que en la novela acosó la Casa durante la vida de Inés la Beata. (17)
\end{abstract}

Efectivamente, además de las semejanzas en términos de construcción, tanto el convento de El Carmen de San Rafael como la Casa de Ejercicios del Obsceno pájaro coinciden en el hecho de acabar siendo bodegas. El primero sirvió de despensa para la feria de la Vega y la Casa de Ejercicios donosiana para los objetos que un grupo de la clase alta guarda a pesar de su deterioro e inutilidad. No obstante lo anterior, si se atiende a la ubicación exacta de ambos edificios, a pesar de tratarse del mismo sector, su localización no coincide, ya que el inmueble propuesto por Browning se ubica en Avenida Independencia y da con las calles Prieto, Picarte y Elena Serrano, en tanto la Casa de Ejercicios del Obsceno pájaro, se localiza en el cuadrante conformado por las calles Colón, Escanilla, Rivera y López; esta información de hecho se corrobora en “Claves de un delirio” cuando Donoso se refiere a la casa que lo inspiró como la "de la calle Cruz” (580).

Por último, las notas que Donoso toma durante su excursión a ese sector de la ciudad que anhela incluir en su ficción revelan a un escritor que logra incorporar esa "ciudad abandonada", ese "Barrio bajo" que lo seducen, no solo a partir de su conocimiento de la historia de Santiago, sino de ser un flâneur, paseante en su ciudad.

\title{
OBRAS CITADAS
}

Browning, Richard. "La arquitectura de la memoria: los edificios y sus significados en 'El obsceno pájaro de la noche’ de José Donoso”. Chasqui: Revista de Literatura Latinoamericana 22.2 (1993): 15-23.

Donoso, José. “Claves de un delirio: los trazos de la memoria en la gestación de Elobsceno pájaro de la noche”. El obsceno pájaro de la noche. Santiago: Alfaguara, 1997. El obsceno pájaro de la noche. Santiago: Alfaguara, 1997.

Revista Iberoamericana, Vol. LXXX, Núm. 246, Enero-Marzo 2014, $147-159$
ISSN 0034-9631 (Impreso) 
“A Small Biography of the Obscene Bird of Night”. Review of Contemporary Fiction 19 (1999): 123-37.

Kerr, Lucille. "Corresponding Archives: Letters from the Latin American Literary Front.” Symposium 61.1 (2007): 75-96.

\section{Cuadernos de Trabajo}

Donoso, José. Notebook 21C. José Donoso Papers. Department of Rare Books and Special Collections, University of Iowa.

Notebook 22. José Donoso Papers. Department of Rare Books and Special Collections, University of Iowa.

Notebook 28. José Donoso Papers. Department of Rare Books and Special Collections, University of Iowa.

Notebook 29. José Donoso Papers. Department of Rare Books and Special Collections, University of Iowa.

\section{BORRADORES MECANOGRAFIADOS}

Donoso, José. Box 3, Folder 3. “Capítulo cinco”. José Donoso Papers. Department of Rare Books and Special Collections, University of Iowa.

Box 3, Folder 3. “Capítulo seis”. José Donoso Papers. Department of Rare Books and Special Collections, University of Iowa.

Box 10, Folder 14 “Capítulo seis”. José Donoso Papers. Department of Rare Books and Special Collections, Princeton University Library.

Revista Iberoamericana, Vol. LXXX, Núm. 246, Enero-Marzo 2014, $147-159$
ISSN 2154-4794 (Electrónico) 
